\title{
Comparative Antioxidative and Antihyperglycemic Profiles of Pneumatophores of Two Mangrove Species Avicennia alba and Sonneratia apetala
}

\author{
Biswajit Biswas, Mimi Golder, Tannami Islam and Samir Kumar Sadhu \\ Pharmacy Discipline, Khulna University, Khulna-9208, Bangladesh
}

(Received: July 31, 2018; Accepted: September 10, 2018; Published (web): December 10, 2018)

\begin{abstract}
Ethanolic extracts of pneumatophores of two mangrove species- Avicennia alba and Sonneratia apetala were studied in vitro for antioxidant capacity by measuring their ability to scavenge free radicals and determining total phenolic, flavonoid and tannin contents. In vivo measurement of antihyperglycemic activity of extracts was done by oral glucose tolerance test. In considering the antioxidant activity, S. apetala extract showed superior $\mathrm{IC}_{50}$ (concentration of sample required to inhibit $50 \%$ of free radicals) value for scavenging DPPH radical $(71.77 \mu \mathrm{g} / \mathrm{ml})$, hydrogen peroxide radical $(97.27 \mathrm{mg} / \mathrm{l})$, hydroxyl radical $(79.62 \mathrm{mg} / \mathrm{l})$ and superoxide anion (108.89 $\mathrm{mg} / \mathrm{l})$. For A. alba, the values for the radical scavenging assays were much higher. In addition, total phenol, flavonoid and tannin content demonstrated by $S$. apetala were $204.03 \mathrm{mgGAE} / \mathrm{g}, 228.68 \mathrm{mgQE} / \mathrm{g}$ and $235.89 \mathrm{mgGAE} / \mathrm{g}$ whereas for $A$. alba, they were $65.52 \mathrm{mgGAE} / \mathrm{g}, 44 \mathrm{mgQE} / \mathrm{g}$ and $37.71 \mathrm{mgGAE} / \mathrm{g}$, respectively. In oral glucose tolerance test, $S$. apetala reduced the blood glucose level to a higher extent than A. alba. So, S. apetala with higher amount of secondary metabolites (phenol, flavonoid, tannin) is a superior source of natural antioxidants and antihyperglycemics.
\end{abstract}

Key words: Avicennia alba, Sonneratia apetala, pneumatophore, antioxidant, radical scavenger, secondary metabolites, antihyperglycemic.

\section{INTRODUCTION}

Any molecule containing one or more unpaired electrons are free radicals. The radicals are constantly produced during the normal oxidation of foods and about $1-4 \%$ of oxygen taken up in the body is converted to free radicals. ${ }^{1}$ The free radical chain reactions are usually produced in the electron transport chain in mitochondria, through liver mixed function oxidases, xanthine oxidase and aldehyde oxidase activity and in macrophage by nitric oxide synthase enzyme. Free radicals mediate lipid peroxidation which in turn stimulate oxidation of sulfhydryl groups, glycation of protein, inactivation of enzymes and fragmentation of DNA bases and deoxyribose leading to cytotoxicity and mutations. ${ }^{2}$

Correspondence to: Samir Kumar Sadhu

E-mail: <sksadhu1969@yahoo.com<

<sksadhu1969@pharm.ku.ac.bd>

Dhaka Univ. J. Pharm. Sci. 17(2): 205-211, 2018 (December) DOI: http://dx.doi.org/10.3329/dujps.v17i2.39177
Although the radicals are important intermediates in natural processes, a variety of pathological conditions like cancer, cardiovascular, inflammatory and respiratory diseases, infertility, aging as well as Parkinson's disease, Alzheimer's disease, multiple sclerosis, liver cirrhosis, muscular dystrophy etc. are caused by them. ${ }^{3,4}$ In addition, radicals or reactive oxygen species (ROS) together with increased triglyceride and lipoprotein levels produced during hyperglycemia due to impaired glucose metabolism play the central role in diabetes complications during diabetes mellitus. Along with oxidative stress, impaired insulin action leading to increased glucose production is also responsible for diabetes. ${ }^{5}$ Therefore, now the search is directed for antioxidative phytochemicals with antihyperglycemic therapeutic effects. 
The body has several mechanisms to counteract the oxidative free radical damage by producing antioxidants. Antioxidants are scavengers of free radicals relative to oxidizable substrate that significantly delay or reduce substrate oxidation. However, single antioxidant molecule reacts with single free radical and hence a constant need to replenish antioxidant resources is important. ${ }^{6}$

Mangrove plants are equipped with very efficient free radical scavenging system due to the hostile environmental conditions like water logging, high salinity, low oxygen, high wind and temperature etc. ${ }^{7}$ They possess a wide variety of phytochemicals such as phenolic compounds (e.g. phenolic acids, flavonoids, quinones, coumarins, lignans, tannins), nitrogen compounds (alkaloids, amines, betalains), vitamins, terpenoids (including carotenoids) and some other endogenous metabolites rich in antioxidant and hypoglycemic activity. ${ }^{8,9}$

Sundarbans is the largest mangrove forest of the world which is on the verge of extinction due to global warming, deforestation, soil erosion and devastating natural calamities. ${ }^{10}$ So, determination of antioxidative and antihyperglycemic activities of pneumatophores of two mangrove species $A$. alba and $S$. apetala along with their total contents of secondary metabolites e.g. phenols, flavonoids and tannins is much demanding and significant.

\section{MATERIALS AND METHODS}

Chemicals. Analytical grade reagents such as 2, 2-diphenyl-1-picryl hydrazyl (DPPH) and FolinCiocalteu reagent along with $\mathrm{Na}_{2} \mathrm{CO}_{3}, \mathrm{NaNO}_{2}, \mathrm{AlCl}_{3}$, $\mathrm{NaOH}, \mathrm{H}_{2} \mathrm{O}_{2}, \mathrm{Na}_{2} \mathrm{HPO}_{4} .2 \mathrm{H}_{2} \mathrm{O}, \mathrm{NaH}_{2} \mathrm{PO}_{4} \cdot 2 \mathrm{H}_{2} \mathrm{O}, 2-$ deoxy-2-ribose, $\mathrm{FeCl}_{3}$, EDTA, TCA, TBA, PMS, ascorbic acid, NBT, NADH were used.

Plant materials. Pneumatophores of the two species Avicennia alba (Family: Acanthaceae) and Sonneratia apetala (Family: Lythraceae) were collected from Sundarbans (Boidyamari, Mongla region) in June, 2016 and identified by the experts at Forestry and Wood Technology Discipline, Khulna University, Khulna, Bangladesh.
Extracts preparation. Cold extraction was carried out for $200 \mathrm{gm}$ of each plant powder with 96\% ethanol. The percent yields for $A$. alba and $S$. apetala were 2.97 and 4.27 , respectively.

\section{Antioxidant Assay}

Qualitative antioxidant activity test. The test was done using pre-coated silica gel TLC plates and developed in polar, medium polar and non-polar solvent systems. Then $0.02 \%$ DPPH solution was applied and color change was noted. ${ }^{11}$

DPPH radical scavenging activity test. DPPH radical scavenging activity of sample extracts was tested by modifications of reported microplate method to determine $\mathrm{IC}_{50}$ values using DPPH. ${ }^{12}$ Thermo Scientific Multiskan Ex microplate photometer was used to measure the absorbance at $517 \mathrm{~nm}$. Antioxidant capacity was determined in terms of $\mathrm{IC}_{50}$, calculated from the $\log$ concentrationpercent inhibition curve. ${ }^{13}$

Hydrogen peroxide scavenging activity test. It was measured in accordance with the method of Keser. ${ }^{14}$ Antioxidant activity was determined in terms of $\mathrm{IC}_{50}$, calculated from the $\log$ concentration-percent inhibition curve.

Hydroxylradical scavenging activity test. The test was performed according to the method described by Elizabeth and Rao with slight modifications. ${ }^{15}$ The activity was measured by determining the competition between deoxyribose and sample extracts for hydroxyl radicals generated by $\mathrm{Fe}^{3+} /$ ascorbate/EDTA/ $\mathrm{H}_{2} \mathrm{O}_{2}$ system (the Fenton reaction). ${ }^{16}$

Superoxide radical scavenging activity test. Superoxide radical scavenging assay is based on the reduction of nitro blue tetrazolium (NBT) in presence of NADH and phenazoniumme thosulphate (PMS). ${ }^{17}$ The test was performed according to the method described by Nishikimi with slight modifications. ${ }^{18}$

\section{Determination of total secondary metabolites}

Total phenolic content determination. Total phenolic content (TPC) was determined by using Folin-Ciocalteu reagent with gallic acid as standard 
and expressed as $\mathrm{mg}$ gallic acid equivalent $(\mathrm{mgGAE}) / \mathrm{gm}$ dried plant extract. ${ }^{19}$

Total flavonoid content determination. Aluminium chloride colorimetric assay was used for the determination of total flavonoid content (TFC) of the sample extracts and quercetin was used as standard. ${ }^{20}$ TFC of extracts, measured from quercet in standard curve was expressed as $\mathrm{mg}$ quercet in equivalent (mgQE)/gm dried plant extract

Total tannin content determination. Total tannin content (TTC) of sample extracts was determined by Folin-Ciocalteure agent and expressed as mg gallic acid equivalent (mgGAE)/gm dried plant extract. $^{21}$

Antihyperglycemic assay. One of the acceptable methods to evaluate the antihyperglycemic activity of plant extracts is oral glucose tolerance evaluation or oral glucose tolerance test (OGTT) ${ }^{22}$ In this test, glucose is given to mice orally and level of glucose in blood sample is measured afterward to determine how quickly it is cleared from blood. In the present study, antihyperglycemic activity of ethanolic extract of pneumatophores of A. alba and S. apetala was screened and compared with the glibenclamide standard.

\section{RESULTS AND DISCUSSION}

In the DPPH assay on TLC plate, any electron or hydrogen donating molecule in mixture will react with and bleach DPPH. Thus, DPPH is reduced from purple to a light yellow component. ${ }^{8} A$. alba and $S$. apetala extracts showed free radical scavenging property indicated by the presence of light yellow spot on the TLC plate. In DPPH radical scavenging activity test, purple colored DPPH has maximum absorption at $517 \mathrm{~nm}$. Scavenging DPPH radical by antioxidants results in a decrease in absorption over time which is proportional to the concentration of radicals being scavenged. ${ }^{23}$ Figure 1 shows the DPPH radical scavenging assay results where $S$. apetala extract revealed an $\mathrm{IC}_{50}$ value of $71.77 \mu \mathrm{g} / \mathrm{ml}$ whereas for A. alba it was $1196.74 \mu \mathrm{g} / \mathrm{ml}$. So, compared to the standard ascorbic acid ( $\mathrm{IC}_{50} 14.42$ $\mu \mathrm{g} / \mathrm{ml}), S$. apetala has relatively high antioxidant property than A. alba.

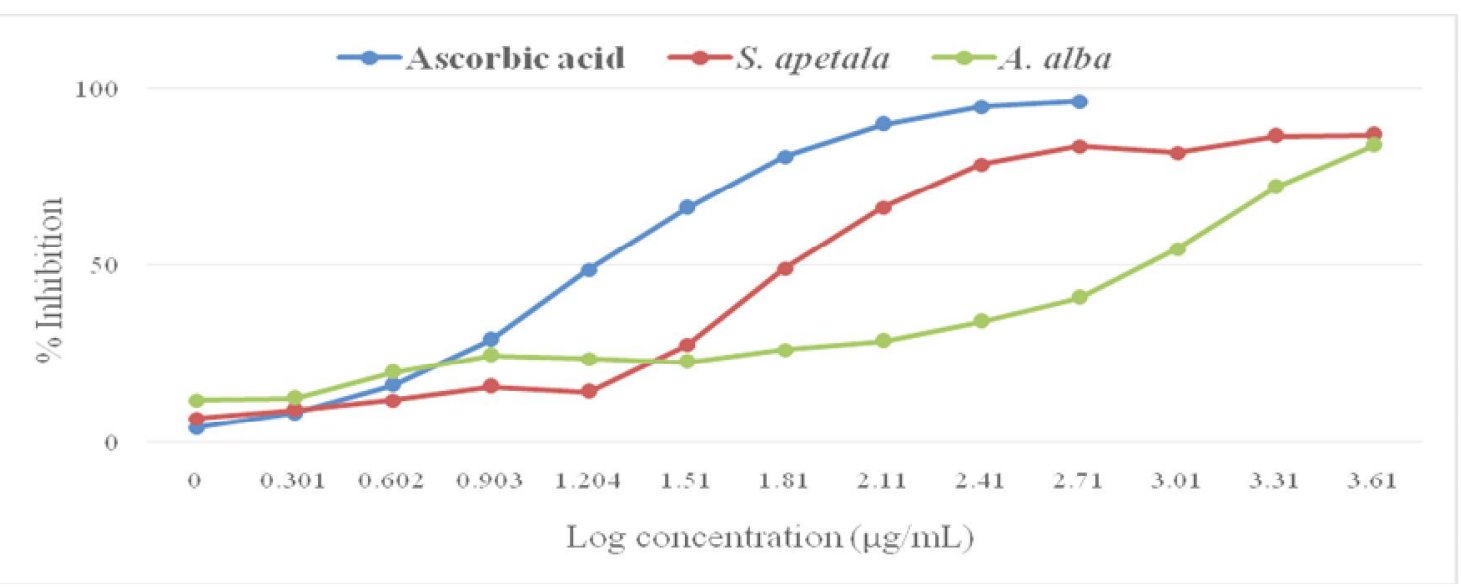

Figure 1.Comparison of \% inhibition of DPPH radicalby ascorbic acid and sample extracts.

Hydrogen peroxide $\left(\mathrm{H}_{2} \mathrm{O}_{2}\right)$ itself is not a free radical rather a weak oxidizing agent that rapidly crosses the cell membranes and reacts with $\mathrm{Fe}^{2+}$ and $\mathrm{Cu}^{2+}$ ions to form hydroxyl radicals inside the cell. ${ }^{16}$ In the hydrogen peroxide scavenging assay, $A$. alba scavenged $\mathrm{H}_{2} \mathrm{O}_{2}$ with an $\mathrm{IC}_{50}$ value of $178.65 \mathrm{mg} / \mathrm{l}$ whereas for $S$. apetala, it was $97.27 \mathrm{mg} / \mathrm{l}$. Again, $\mathrm{IC}_{50}$ value for ascorbic acid standard was $83.95 \mathrm{mg} / \mathrm{l}$ (Figure 2). Therefore, S. apetala showed higher scavenging ability than A. alba.

In hydroxyl radical scavenging activity test, hydroxyl radicals were produced by incubating 
ferric-EDTA with ascorbic acid and $\mathrm{H}_{2} \mathrm{O}_{2}$ at $\mathrm{pH}$ 7.4. Then the radical was reacted with 2-deoxy-2-ribose to generate a MDA-like product that forms a pink chromogen upon heating with TBA at low $\mathrm{pH}$. The sample extracts added to the reaction mixture exerted antioxidant activity by competing with deoxyribose for hydroxyl radicals and thus preventing the reaction. ${ }^{16}$ A alba extract displayed hydroxyl radical scavenging activity with an $\mathrm{IC}_{50}$ value of 132.43 $\mathrm{mg} / \mathrm{l}$, for $S$. apetala it was $79.62 \mathrm{mg} / \mathrm{l}$ and for ascorbic acid standard, it was $62.95 \mathrm{mg} / \mathrm{l}$ (Figure 3). The $\mathrm{IC}_{50}$ values indicate that $S$. apetala plant extract is a better hydroxyl radical scavenger than the $A$. alba.

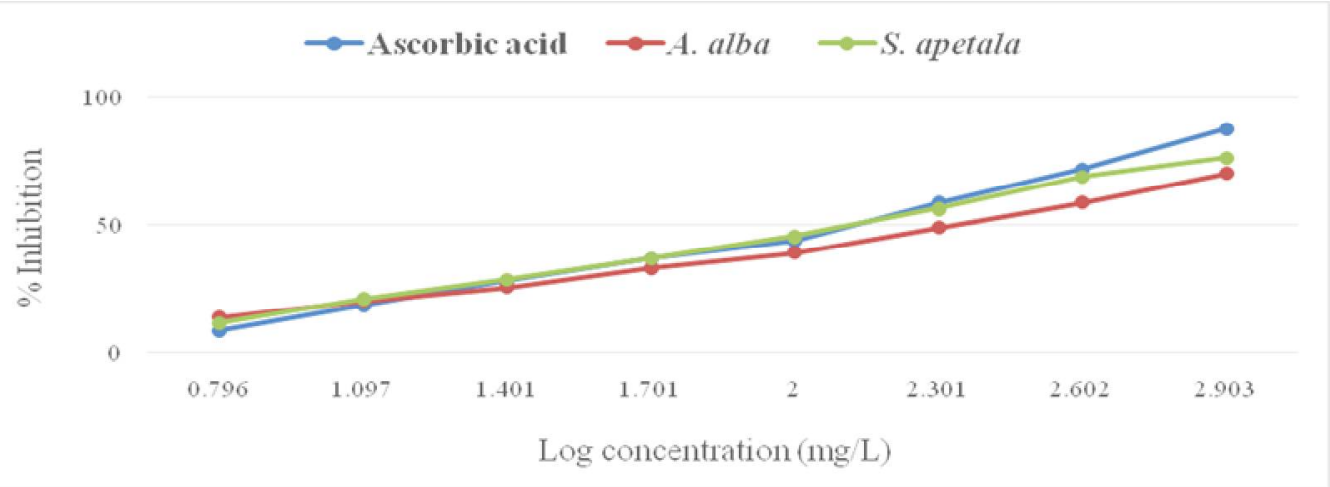

Figure 2. Comparison of \% inhibition of $\mathrm{H}_{2} \mathrm{O}_{2}$ by ascorbic acid and sample extracts.

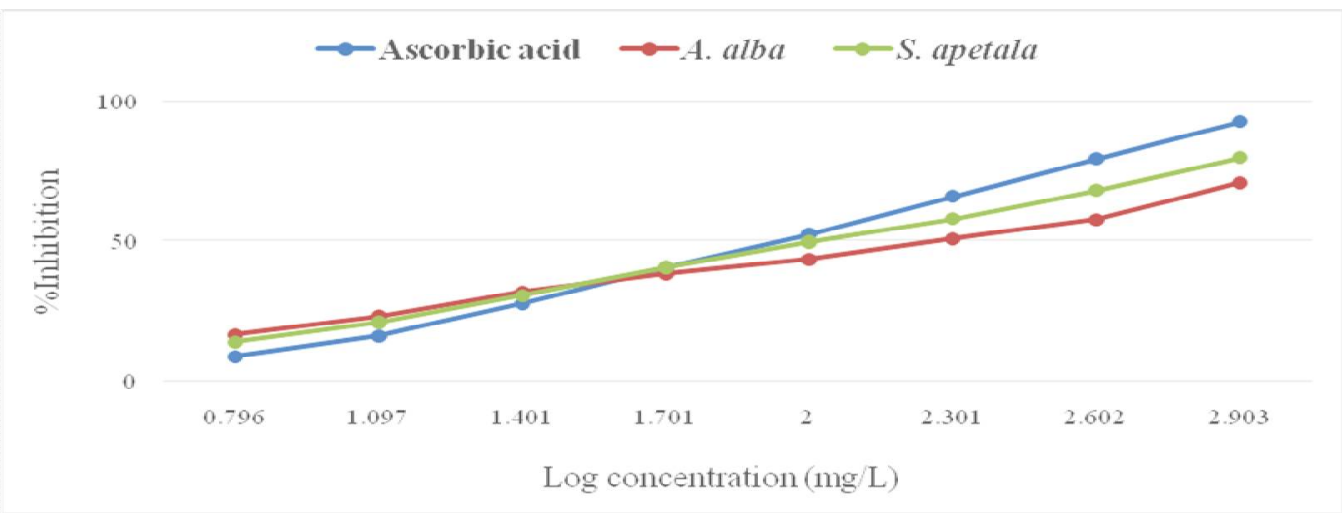

Figure 3. Comparison of \% inhibition of hydroxyl radicalby ascorbic acid and sample extracts.

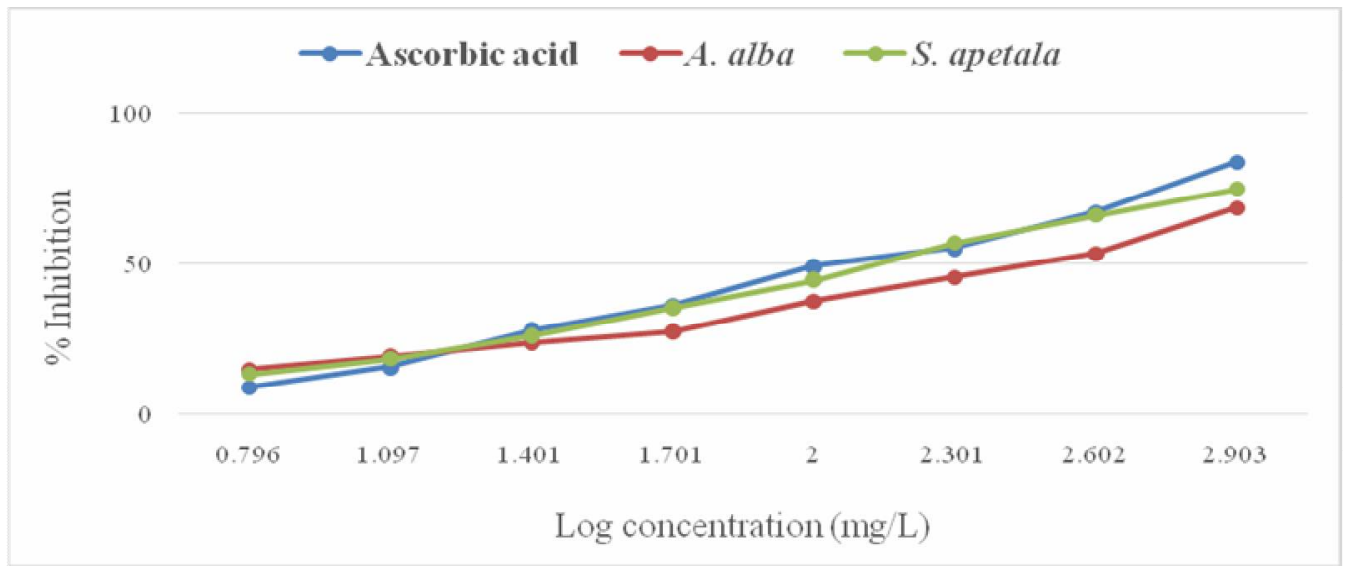

Figure 4. Comparison of \% inhibition of superoxide radical by ascorbic acid and sample extracts. 
In the superoxide radical scavenging activity test, superoxide anion $\left(\mathrm{O}^{2-}\right)$ derived from dissolved PMSNADH coupling reaction reduces NBT to a purple form and hence NBT is the probe to quantify its $\left(\mathrm{O}^{2-}\right)$ concentration. The reduction of absorbance at 560 $\mathrm{nm}$ after incubation of tested samples indicated the consumption of superoxide anion in the reaction mixture. ${ }^{23}$ Figure 4 shows that the $\mathrm{IC}_{50}$ value for $A$. alba extract is $257.04 \mathrm{mg} / \mathrm{l}$ and for $S$. apetala it is $108.89 \mathrm{mg} / \mathrm{L}$ compared to the ascorbic acid standard ( $\left.\mathrm{IC}_{50} 92.26 \mathrm{mg} / \mathrm{l}\right)$. So, $S$. apetala is a better scavenger of superoxide radical than A. alba.

Plant secondary metabolites like polyphenols, flavonoids and tannins were suggested to have evolved for protecting the plant from herbivores. ${ }^{24}$ In human, many phenolics are responsible for reducing the risk of developing chronic diseases like cardiovascular disease, cancer, diabetes, etc. Tannins have marked anti-tumor, anti-viral, and anti-HIV activities along with inhibition of lipid peroxidation and plasmin, mediation of DNA nicking and amelioration of renal failure etc. On the other hand, flavonoids exhibit anti-spasmodic, anti-inflammatory, and anti-allergic activities as well as protective effects against vascular and hepatic disorders. By investigating the mechanism of action of these effects, antioxidant and free-radical scavenging actions were found responsible. ${ }^{25}$

In previous studies, different polyphenols were isolated from different parts of A. alba and $S$. apetala. Three new naphthoquinones, named avicequinone- $\mathrm{A},-\mathrm{B},-\mathrm{C}$ and their analogues avicenol A, B, C were reported in A. alba. ${ }^{26}$ On the other hand, $S$. apetala was screened for secondary metabolites and different polyphenols, anthocyanins, flavonoid aglycones and flavonoid glycosides along with gallic acid, (+)-catechin, (-)-epicatechin, ellagic acid and quercetin were that exhibit strong antioxidant activity. ${ }^{27}$ Here, total phenolic content of A. alba was $65.52 \mathrm{mg}$ gallic acid equivalent (mgGAE)/g and for S. apetala it was 204.03 $\mathrm{mgGAE} / \mathrm{g}$. However, total flavonoid content was $44.0 \mathrm{mgQE} / \mathrm{g}$ for $A$. alba and $228.68 \mathrm{mgQE} / \mathrm{g}$ for $S$. apetala. As far as total tannin content was concerned, S. apetala dominated with a value of 235.89 $\mathrm{mgGAE} / \mathrm{g}$, whereas for $A$. alba it was 37.71 $\mathrm{mgGAE} / \mathrm{g}$.

In considering the antihyperglycemic effect, oral glucose tolerance evaluation is a standard test for measuring how quickly exogenous glucose can be cleared from blood. Glucose uptake of cells from the blood is controlled by insulin and impairment in glucose tolerance (i.e., higher time to clear certain amount of glucose) indicates problems with conservation of glucose homeostasis i.e. carbohydrate metabolism, insulin resistance, diabetes etc. ${ }^{28}$ In evaluating the antihyperglycemic activity of the pneumatophores of plant extracts, S. apetala showed significant effect rather than A. alba at doses 250 and $500 \mathrm{mg} / \mathrm{kg}$ body weight at 60 and $120 \mathrm{~min}$ after the administration of glucose (Table 1). Possible mechanisms of antihyperglycemic activity for the plant extract include substantial free radical scavenging activity, increased insulin releasing activity, insulin mimetic activity, altered glucose utilization, regeneration of pancreatic Islets of Langerhans and transport of blood glucose to the peripheral tissue mediated by the presence of secondary metabolites such as triterpenes, steroids, flavonoids, alkaloids, phenolics etc. ${ }^{9}$

Table 1. Blood glucose level (mmol/l) of plant extracts for oral glucose tolerance evaluation.

\begin{tabular}{lccccccc}
\hline $\begin{array}{l}\text { Sample } \\
\text { extract }\end{array}$ & $\begin{array}{c}\text { DRSA } \\
\left(\mathrm{IC}_{50} \mu \mathrm{g} / \mathrm{ml}\right)\end{array}$ & $\begin{array}{c}\text { HPSA } \\
\left(\mathrm{IC}_{50} \mathrm{mg} / \mathrm{l}\right)\end{array}$ & $\begin{array}{c}\text { HRSA } \\
\left(\mathrm{IC}_{50} \mathrm{mg} / \mathrm{l}\right)\end{array}$ & $\begin{array}{c}\text { SRSA } \\
\left(\mathrm{IC}_{50} \mathrm{mg} / \mathrm{l}\right)\end{array}$ & $\begin{array}{c}\text { TPC }(\mathrm{mg} \\
\text { GAE/g })\end{array}$ & $\begin{array}{c}\text { TFC }(\mathrm{mg} \\
\text { QE/g })\end{array}$ & $\begin{array}{c}\text { TTC(mg } \\
\text { GAE/g) }\end{array}$ \\
\hline A. alba & 1196.74 & 178.65 & 132.43 & 257.04 & 65.52 & 44.0 & 37.71 \\
S. apetala & 71.77 & 97.27 & 79.62 & 108.89 & 204.03 & 228.68 & 235.89 \\
\hline
\end{tabular}

Values are means \pm S.D., $\mathrm{n}=5, \mathrm{p}<0.05(*), \mathrm{p}<0.01(* *)$. 
Table 2. $\mathrm{IC}_{50}$ values of different scavenging assays and total content of secondary metabolites (phenolics, flavonoid and tannin) of sample extracts.

\begin{tabular}{lccc}
\hline \multirow{2}{*}{$\begin{array}{l}\text { Treatment } \\
\text { group }\end{array}$} & At $0 \mathrm{~min}$ & Bt $60 \mathrm{~min}$ & At $120 \mathrm{~min}$ \\
\cline { 2 - 4 } & $5.88 \pm 0.15$ & $8.23 \pm 0.78$ & $7.70 \pm 0.40$ \\
\hline Control & $5.77 \pm 0.12$ & $4.17 \pm 1.01^{* *}$ & $3.58 \pm 0.69^{* *}$ \\
Glibenclamide & $5.4 \pm 0.49^{*}$ & $8.33 \pm 0.91$ & $7.45 \pm 0.59$ \\
A. alba $(250 \mathrm{mg})$ & $5.38 \pm 0.37^{* *}$ & $8.28 \pm 1.48$ & $7.42 \pm 0.63$ \\
A. alba $(500 \mathrm{mg})$ & $4.18 \pm 0.37^{* *}$ & $7.92 \pm 0.31$ & $5.15 \pm 0.40^{* *}$ \\
S. apetala $(250 \mathrm{mg})$ & $4.22 \pm 0.33^{* *}$ & $7.17 \pm 0.45^{* *}$ & $5.12 \pm 0.31^{* *}$ \\
S. apetala $(500 \mathrm{mg})$ & & & \\
\hline
\end{tabular}

DRSA (DPPH Radical Scavenging Activity), HPSA (Hydrogen Peroxide Scavenging Activity), HRSA (Hydroxyl Radical Scavenging Activity), SRSA (Superoxide Radical Scavenging Activity), TPC (Total Phenolic Content), TFC (Total Flavonoid Content), Total Tannin Content (TTC).

When all the calculated data for the evaluation of antioxidative activity was accumulated in a single table (Table 2), a definite linear correlation was found between free radical scavenging effect and amount of total secondary metabolites of the samples. In addition, substantially higher antihyperglycemic activity of $S$. apetala was also supported by its superior contents of phenol, flavonoid, tannin and other secondary metabolites. So, on the basis of these results, it could be concluded that $S$. apetala might be a prospective resource of antioxidative and antihyperglycemic constituents.

\section{CONCLUSION}

Based on the obtained data of present study, it can be concluded that ethanolic extract of $S$. apetala pneumatophore, which contains large amounts of phenolic compounds, flavonoids and tannins, exhibits a higher extent of antioxidative free radical scavenging and antihyperglycemic activity than $A$. alba which contains less amount of secondary metabolites. These in vitro and in vivo assays are indicators of the plant extracts as potential source of natural antioxidants and antihyperglycemics which might be essential in the prevention of various oxidative stresses, diabetes and related physiological disorders.

\section{ACKNOWLEDGEMENTS}

This project was funded by the Ministry of Education, Bangladesh in advanced research aid program in education and partly by Khulna University Research Cell (KURC). The authors would also like to thank the authority of Pharmacy Discipline, Khulna University for whole hearted support to carry out this research project and the experts at Forestry and Wood Technology Discipline, Khulna University for identification of plant samples.

\section{REFERENCES}

1. Veerabathran, S.K., Janaky, S. and Sekar, T. 2011. Antioxidant status of leaves of Caesalpiniabonduc. Int. J. Pharm. App. 2, 262-266.

2. Ara, N. and Nur, H. 2009. In vitro antioxidant activity of methanolic leaves and flowers extracts of Lippiaalba. Res. J. Medicine Med. Sci. 4, 107-110.

3. Sarma, A.D., Mallick, A.R. and Ghosh, A.K. 2010. Free radicals and their role in different clinical conditions: an overview. Int. J. Pharm. Sci. Res. 1, 185-192.

4. Pham-Huy, L.A., He, H. and Pham-Huy, C. 2008. Free radicals, antioxidants in disease and health. Int. J. Biomed. Sci. 4, 89-96.

5. Bonnefont-Rousselot, D. 2002. Glucose and reactive oxygen species. Curr. Opin. Clin. Nutr. Metab. Care. 5, 561-568.

6. Pourmorad, F., Hosseinimehr, S.J. and Shahabimajd, N. 2006. Antioxidant activity, phenol and flavonoid contents of some selected Iranian medicinal plants. Afr. J. Biotechnol. 5, 1142-1145.

7. Thatoi, H.N., Patra, J.K. and Das, S.K. 2014. Free radical scavenging and antioxidant potential of mangrove plants: A review. Acta. Physiol. Plant. 36, 561-579.

8. Masokoab, P. and Elof, J.N. 2007. Screening of twenty-four South African Combretum and six Terminalia species (Combretaceae) for antioxidant activities. Afr. J. Tradit. Complement. Altern. Med. 4, 231-239. 
9. Das, S.K., Samantaray, D., Patra, J.K., Samanta, L. and Thatoi, H. 2016. Antidiabetic potential of mangrove plants: A review. Front. Life Sci. 9, 75-88.

10. Aziz, A. and Paul, A.R. 2015. Bangladesh Sundarbans: Present status of the environment and biota. Diversity 7, 242269.

11. Dwivedy, B.N., Dabral, P. and Kumar, R. 2014. Antioxidant activity of ethanolic extract of Heritierafomes leaves. World J. Pharm. Res. 6, 1713-1723.

12. Yokozawa, T., Chen, C.P., Dong, E., Tanaka, T., Nonaka, G. and Nishioka, I. 1998. Study on the inhibitory effect of tannins and flavonoids against the 1,1-diphenyl-2 picrylhydrazyl radical. Biochem. Pharmacol. 56, 213-222.

13. Sadhu, S.K., Okuyama, E., Fujimoto, H. and Ishibashi, M. 2003. Seperation of Leucasaspera, a medicinal plant of Bangladesh, guided by prostaglandin inhibitory and antioxidant activities. Chem. Pharm. Bull. 51, 595-598.

14. Keser, S., Celik, S., Turkoglu, S., Yilmaz, O. and Turkoglu, I. 2012. Hydrogen peroxide radical scavenging and total antioxidant activity of Hawthorn. Chem. J. 2, 9-12.

15. Elizabeth, K. and Rao, M.N.A. 1989. Oxygen radical scavenging activity of curcumin. Intl. J. Pharm. 58, 237-240.

16. Hazra, B., Biswas, S. and Mandal, N. 2008. Antioxidant and free radical scavenging activity of Spondiaspinnata. B.M.C. Complement. Altern. Med. 8, 1-10.

17. Elizabeth, S.B. and Murugesan, K. 2012. Evaluation of antioxidant potential of Morinda citrifolia L. root extract. Int. Res. J. Pharmaceuticals. 02, 106-111.

18. Nishikimi, M., Rao, N.A. and Yagi, K. 1972. The occurrence of superoxide anion in the reaction of reduced phenazinemethosulphate and molecular oxygen. Biochem. Biophys. Res. Commun. 46, 849-854.

19. McDonald, S., Prenzler, P.D., Autolovich, M. and Robards, K. 2001. Phenolic content and antioxidant activity of olive extracts. Food Chem. 73, 73-84.
20. Marinova, D., Ribarova, F. and Atanassova, M. 2005. Total phenolics and total flavonoids in Bulgarian fruits and vegetables. J. Univ. Chem. Technol. Metallurgy 40, 255-260.

21. Tambe, V.D. and Bhambar, R.S. 2014. Estimation of total phenol, tannin, alkaloid and flavonoid in Hibiscus tiliaceus Linn. wood extracts. J. Pharmacogn. Phytochem. 2, 41-47.

22. Bnouham, M., Merhfour, F.Z., Ziyyat, A., Mekhfi, H., Aziz, M. and Legssyer, A. 2003. Antihyperglycemic activity of the aqueous extract of Urticadioica. Fitoterapia 74, 677-681.

23. Liang, N. and Kitts, D.D. 2014. Antioxidant property of coffee components: Assessment of methods that define mechanisms of action. Molecules 19, 19180-19208.

24. Banerjee, D., Chakrabarti, S., Hazra, A.K., Banerjee, S., Ray, J. and Mukherjee, B. 2008. Antioxidant activity and total phenolics of some mangroves in Sundarbans. Afr. J. Biotechnol. 7, 805-810.

25. Yokozawa, T., Chen, C.P., Dong, E., Tanaka, T., Nonaka, G.I. and Nishiok, I. 1998. Study on the inhibitory effect of tannins and flavonoids against the 1,1-diphenyl-2picrylhydrazyl radical. Biochem. Pharmacol. 56, 213-222.

26. Ito, C., Katsuno, S., Kondo, Y., Tan, H.T.W. and Furukaw, H.2000. Chemical constituents of Avicenniaalba: Isolation and structural elucidation of new naphthoquinones and their analogues. Chem. Pharm. Bull. 48, 339-343.

27. Hossain, S.J., Iftekharuzzaman, M., Haque, M.A., Saha, B., Moniruzzaman, M., Rahman, M.M. and Hossain, H. 2016. Nutrient compositions, antioxidant activity and common phenolics of Sonneratia apetala (Buch.-Ham.) fruit. Int. J. Food Prop. 19, 1080-1092.

28. Joy, K. and Kuttan, R. 1999. Anti-diabetic activity of Picrorrhiza kurroa extract. J. Ethnopharmacol. 67, 143-148. 